\title{
Article \\ Endogenous Levels of Gamma Amino-Butyric Acid Are Correlated to Glutamic-Acid Decarboxylase Antibody Levels in Type 1 Diabetes
}

\author{
Henrik Hill ${ }^{1}$, Andris Elksnis ${ }^{2}\left(\mathbb{D}\right.$, Per Lundkvist $^{3}$, Kumari Ubhayasekera ${ }^{4}$, Jonas Bergquist ${ }^{4}\left(\mathbb{D}\right.$, Bryndis Birnir $^{2} \mathbb{D}$, \\ Per-Ola Carlsson ${ }^{2,3}$ and Daniel Espes ${ }^{5,6, *}$ \\ 1 Department of Women's and Children's Health, Uppsala University, 75185 Uppsala, Sweden; \\ henrik.hill@kbh.uu.se \\ 2 Department of Medical Cell Biology, Uppsala University, 75123 Uppsala, Sweden; \\ andris.elksnis@mcb.uu.se (A.E.); Bryndis.Birnir@mcb.uu.se (B.B.); per-ola.carlsson@mcb.uu.se (P.-O.C.) \\ 3 Department of Medical Sciences, Uppsala University, 75309 Uppsala, Sweden; per-lundkvist@medsci.uu.se \\ 4 Department of Chemistry, Analytical, BMC, Uppsala University, 75237 Uppsala, Sweden; \\ Kumari.Ubhayasekera@kemi.uu.se (K.U.); Jonas.Bergquist@kemi.uu.se (J.B.) \\ 5 Science for Life Laboratory, Department of Medical Cell Biology, Uppsala University, 75123 Uppsala, Sweden \\ 6 Science for Life Laboratory, Department of Medical Sciences, Uppsala University, 75309 Uppsala, Sweden \\ * Correspondence: daniel.espes@scilifelab.uu.se
}

Citation: Hill, H.; Elksnis, A.; Lundkvist, P.; Ubhayasekera, K.; Bergquist, J.; Birnir, B.; Carlsson, P.-O.; Espes, D. Endogenous Levels of Gamma Amino-Butyric Acid Are Correlated to Glutamic-Acid Decarboxylase Antibody Levels in Type 1 Diabetes. Biomedicines 2022, 10, 91. https://doi.org/10.3390/ biomedicines 10010091

Academic Editors: Björn Tyrberg and Maria Sörhede Winzell

Received: 30 November 2021 Accepted: 28 December 2021 Published: 31 December 2021

Publisher's Note: MDPI stays neutral with regard to jurisdictional claims in published maps and institutional affiliations.

Copyright: (C) 2021 by the authors. Licensee MDPI, Basel, Switzerland. This article is an open access article distributed under the terms and conditions of the Creative Commons Attribution (CC BY) license (https:// creativecommons.org/licenses/by/ $4.0 /)$
Abstract: Gamma-aminobutyric acid (GABA) is an important inhibitory neurotransmitter in the central nervous system (CNS) and outside of the CNS, found in the highest concentrations in immune cells and pancreatic beta-cells. GABA is gaining increasing interest in diabetes research due to its immune-modulatory and beta-cell stimulatory effects and is a highly interesting drug candidate for the treatment of type 1 diabetes (T1D). GABA is synthesized from glutamate by glutamic acid decarboxylase (GAD), one of the targets for autoantibodies linked to T1D. Using mass spectrometry, we have quantified the endogenous circulating levels of GABA in patients with new-onset and long-standing T1D and found that the levels are unaltered when compared to healthy controls, i.e., T1D patients do not have a deficit of systemic GABA levels. In T1D, GABA levels were negatively correlated with IL-1 beta, IL-12, and IL-15 15 and positively correlated to levels of IL-36 beta and IL-37. Interestingly, GABA levels were also correlated to the levels of GAD-autoantibodies. The unaltered levels of GABA in T1D patients suggest that the GABA secretion from beta-cells only has a minor impact on the circulating systemic levels. However, the local levels of GABA could be altered within pancreatic islets in the presence of GAD-autoantibodies.

Keywords: type 1 diabetes; GABA; islets of Langerhans GAD-autoantibodies

\section{Introduction}

The amino acid gamma-aminobutyric acid (GABA) is an essential and mainly inhibitory neurotransmitter in the central nervous system (CNS). Endogenous GABA acts as a mediator in peripheral tissues and is found at its highest concentrations in immune cells [1] and pancreatic beta-cells [2]. GABA is synthesized from glutamate by the enzyme glutamic acid decarboxylase (GAD), which is present in two isoforms, GAD65 and GAD67 [3]. Autoantibodies against GAD are associated with type 1 diabetes (T1D), and a high GAD-titer is a strong predictor of rapid loss of beta-cell mass [4].

Endogenous GABA levels can be detected in blood in concentrations high enough to activate GABA-A receptors [5]; however, where it originates from and how the levels are regulated is not fully understood. It can be secreted from circulating immune cells [6,7] and pancreatic beta-cells [8]. Additionally, GABA synthesized in the brain can reach the circulation via the recently discovered glymphatic drainage system [9]. GABA exerts a predominantly suppressive effect on immune cells, inhibiting the production of 
inflammatory cytokines via the GABA-A receptor, which is expressed on T-cells, B-cells, and some mononuclear cells [6]. We recently found that GABA regulates the release of inflammatory cytokines from peripheral blood mononuclear cells and CD4+ T-cells. Its effects were especially potent on immune cells derived from patients with T1D [10]. Additionally, in a sub-set, we detected circulating levels of GABA in plasma that correlated to several cytokines [10].

In addition to its immune-modulatory effects, GABA has also been found to stimulate beta-cell regeneration via both beta-cell proliferation and trans-differentiation [11-13]. In experimental studies, GABA has even been able to reverse diabetes by restoring the betacell mass [14]. GABA is therefore highly interesting as a potential drug candidate for regenerative therapies in T1D. We have recently demonstrated the safety of a controlledrelease GABA analog [15], and are currently conducting the first clinical proof-of-concept study investigating the potential stimulatory effects of GABA on beta-cell proliferation in patients with manifest T1D (clinicaltrials.gov ID NCT03635437).

However, little is known about how the endogenous levels of GABA are related to the disease state and metabolic features in T1D. Hence, we have investigated endogenous plasma levels of GABA in both healthy controls and patients with long-standing and new-onset T1D.

\section{Materials and Methods}

The study was approved by the Regional Research Ethical Committee in Uppsala and was conducted in accordance with the principles of the Declaration of Helsinki as revised in 2013. All participants were provided oral and written information and signed a written consent before inclusion in the study. In total, $n=45$ healthy controls (HC), $n=60$ patients with long-standing T1D, and $n=13$ patients with new-onset T1D were included.

All visits were performed in the morning after an overnight fast. Peripheral venous blood was collected for analyses at the Clinical Chemistry Laboratory, Uppsala University Hospital. According to clinical routine, patients were considered positive for autoantibodies if anti-GAD was $>5 \mathrm{IU} / \mathrm{mL}$ and anti-IA2 $>7 \mathrm{kU} / \mathrm{L}$. Plasma C-peptide was detectable if above $0.01 \mathrm{nmol} / \mathrm{L}$ using the standard clinical assay. C-peptide measurements were missing for $n=2$ healthy controls. Plasma was collected from EDTA vials and stored at $-70{ }^{\circ} \mathrm{C}$ for later analysis of GABA and cytokines. Plasma aliquots were available for cytokine analysis from $n=27 \mathrm{HC}, n=45$ long-standing T1D, and $n=11$ new-onset T1D patients.

Plasma levels of GABA were analyzed by a validated protocol based on ultra-performance liquid chromatography tandem mass spectrometry. Samples were prepared by spiking with $30 \mu \mathrm{L}$ of $100 \mathrm{ng} / \mathrm{mL}$ corresponding d6GABA into $100 \mu \mathrm{L}$ plasma followed by liquid-liquid extraction after protein precipitation with methanol prior to the analysis. The chromatographic separation of the targeted GABA was achieved by using ultra-performance liquid chromatography (UPLC, Waters ACQUITY ${ }^{\circledR}$, Milford, MA, USA) coupled with tandem mass spectrometry $\left(\mathrm{XEVO}^{\circledR} \mathrm{TQ}-\mathrm{S}\right.$, Milford, MA, USA). The chromatographic separation of GABA was achieved on a HILIC, SS $(100 \times 2.1 \mathrm{~mm}, 1.8 \mu \mathrm{m}$; HILICON, Umeå, Sweden $)$ at $40^{\circ} \mathrm{C}$. The gradient elution was carried out with a binary solvent system consisting of $20 \mathrm{mM}$ NH4OAc in water (solvent A), acetonitrile (solvent B) at a flow rate of $0.35 \mathrm{~mL} / \mathrm{min}$. The applied linear gradient profile started with $10 \%$ A for $5 \mathrm{~min}$. Then, in $8 \mathrm{~min}$, the proportion of solvent $\mathrm{A}$ was increased to $35 \%$. Subsequently, in $8.5 \mathrm{~min}$, the proportion of solvent A was decreased to $10 \%$. This mobile phase condition was kept for $12 \mathrm{~min}$. Finally, the mobile phase was switched back to initial conditions in $0.10 \mathrm{~min}$, and the column was allowed to re-equilibrate. A $5 \mu \mathrm{L}$ aliquot of each sample was injected for analysis and the total analytical time was $12 \mathrm{~min}$.

The mass spectrometric detection was performed using electrospray ionization in the positive ionization mode (ESI+) with nitrogen and argon serving as desolvation and collision gas, respectively. The data acquisition range was 100-500 $\mathrm{m} / \mathrm{z}$. Quantification was based on a multiple reaction monitoring (MRM) method with a deuterated isotope internal standard (d6GABA). Two specific transitions were chosen, one for confirmation (the "qualifier") and one for quantification (the "quantifier"), $104.06>69.06 ; 104.06>87.08$ for 
GABA, respectively. The linearity of GABA was evaluated over a range of concentrations $(1-5000 \mathrm{ng} / \mathrm{mL})$, and correlation coefficients $\left(r^{2}\right)$ were 0.998 . The limit of quantification $(\mathrm{LOQ}$, single to noise ratio $=10)$ and coefficient of variation $(\mathrm{CV})$ of GABA assay was $0.5 \mathrm{ng} / \mathrm{mL}$, less than $10 \%$, respectively. Precision was estimated by running quality control samples in five replicates on the same day, and three independent days; intra-assay CV ranged from $5.12-7.34 \%$, while inter-assay $\mathrm{CV}$ was $2.46-5.73 \%$. The recovery of the GABA assay was $85 \%$. All data were acquired in centroid mode, analyzed, and processed using the MassLynxTM 4.2 software (Waters, Milford, MA, USA). Duplicate analyses of each sample were carried out, and the average values were reported $(\mathrm{CV}<5 \%)$.

Circulating cytokines were analyzed with magnetic bead-based Luminex using two commercially available assays (cat. no. HTH17MAG-14K and cat. no. HCYP4MAG64K) from Merck Millipore (Burlington, MA, USA) according to the manufacturer's protocol. A complete list of included cytokines is provided in Supplementary Table S1. The analyses were performed at the Plasma Profiling Unit, SciLifeLab (Stockholm, Sweden). Of the analyzed cytokines, IL-22, IL-24, IL-34, and IL-35 were excluded from analysis since $>50 \%$ of the samples were below the detection level. For the remaining parameters, undetectable samples were assigned a numeric value corresponding to half of the lowest level of detection (single-value imputation).

Statistical analyses were conducted with GraphPad Prism version 9. Comparison between three groups was performed with a one-way ANOVA using Dunnet's post hoc test for comparison with healthy controls. Comparisons between two groups were performed using an unpaired two-tailed $t$-test. Correlations were computed with the Spearman rank-order test. Data are presented as means \pm SEM. $p$-values $<0.05$ were considered statistically significant.

\section{Results}

Healthy controls and patients were of similar age, and the gender distribution within the groups was similar. The patients with long-standing T1D had a higher BMI when compared to healthy controls. As expected, fasting glucose levels and $\mathrm{HbA1c}$ were higher in the T1D patients. None of the healthy controls had GAD- or IA-2 autoantibodies, for complete descriptive characteristics, see Table 1.

Table 1. Descriptive data of healthy controls and patients with type 1 diabetes.

\begin{tabular}{cccc}
\hline Parameter & HC $(\boldsymbol{n}=\mathbf{4 5})$ & T1D $(\boldsymbol{n}=\mathbf{6 0})$ & New-Onset T1D $(\boldsymbol{n}=\mathbf{1 3})$ \\
\hline Female $(n,(\%))$ & $24(53 \%)$ & $28(47 \%)$ & $6(46 \%)$ \\
\hline Age (years) & $29.8 \pm 1.6$ & $28.4 \pm 0.8$ & $24.2 \pm 0.7$ \\
\hline Disease duration (years) & $\mathrm{n} / \mathrm{a}$ & $16.3 \pm 0.8$ & $0.17 \pm 0.03$ \\
\hline Age at onset (years) & $\mathrm{n} / \mathrm{a}$ & $12.1 \pm 0.9$ & $24.2 \pm 0.7$ \\
\hline BMI $\left(\mathrm{kg} / \mathrm{m}^{2}\right)$ & $23.1 \pm 0.4$ & $24.7 \pm 0.5^{*}$ & $22 \pm 0.6$ \\
\hline fP-Glucose $(\mathrm{mmol} / \mathrm{L})$ & $5.3 \pm 0.07$ & $11.6 \pm 0.6^{* * *}$ & $8.1 \pm 1.0 *$ \\
\hline HbA1c $(\mathrm{mmol} / \mathrm{mol})$ & $31.2 \pm 0.4$ & $61.9 \pm 1.7^{* * *}$ & $69.2 \pm 7.4^{* * *}$ \\
\hline Detectable C-peptide $(n, \%)$ & $43(100 \%)$ & $13\left(22^{*}\right)$ & $13(100 \%)$ \\
\hline C-peptide $(\mathrm{nmol} / \mathrm{L})$ & $0.61 \pm 0.03$ & $0.08 \pm 0.03 * * *$ & $0.3 \pm 0.03 * * *$ \\
\hline GABA $(\mathrm{ng} / \mathrm{mL})$ & $14.1 \pm 0.6$ & $15.6 \pm 0.5$ & $13.3 \pm 0.7$ \\
\hline GAD positive $(n, \%)$ & $0(0 \%)$ & $34(57 \%)$ & $10(77 \%)$ \\
\hline IA-2 positive $(n, \%)$ & $0(0 \%)$ & $31(52 \%)$ & $10(77 \%)$ \\
\hline
\end{tabular}

Descriptive clinical data for healthy controls (HC) and individuals with long-standing type 1 diabetes (T1D)

Plasma C-peptide was analyzed according to clinical routine and was detectable if above $0.01 \mathrm{nmol} / \mathrm{L}$. Cpeptide concentrations were missing for $n=2 \mathrm{HC}$ and are only reported for long-standing T1D patients with detectable levels $(n=13)$. Patients were considered positive for autoantibodies if anti-GAD was $>5 \mathrm{IU} / \mathrm{mL}$ and anti-IA2 $>7 \mathrm{kU} / \mathrm{L}$ (according to clinical routine). Statistical comparisons based on one-way ANOVA using Dunnet's test based on comparisons with HC. ${ }^{*}$ denotes $p<0.05$ and ${ }^{* * *} p<0.001$. All values are given as mean \pm SEM. Abbreviations: BMI, body mass index; fP, fasting plasma; HbA1c, glycated hemoglobin; GAD, glutamic acid decarboxylase; IA2, tyrosine phosphatase-like protein islet antigen-2. 
The endogenous systemic levels of GABA are not decreased in T1D patients when compared to HC (Table 1). In addition, the levels are also similar in patients with newonset T1D (Figure 1A). Among the patients with long-standing T1D, C-peptide was still detectable in $n=13$ individuals, i.e., meaning that there are functionally remaining beta-cells. However, the GABA levels were similar in the C-peptide-positive patients compared to patients without detectable C-peptide (15.4 \pm 0.75 vs. $15.6 \pm 0.6 ; p=0.85)$. The GABA levels were similar also when comparing patients without detectable C-peptide with healthy controls (15.6 \pm 0.6 vs. $14.1 \pm 0.6 ; p=0.06)$.

A

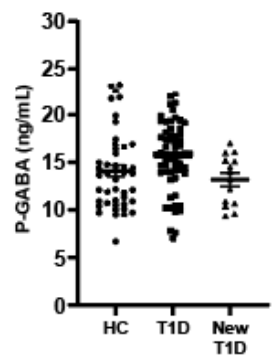

D

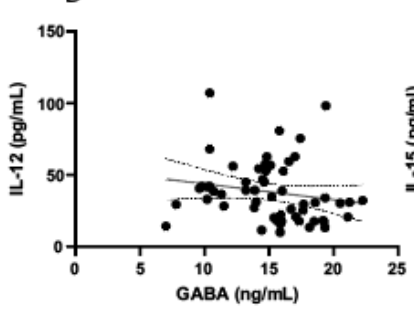

G

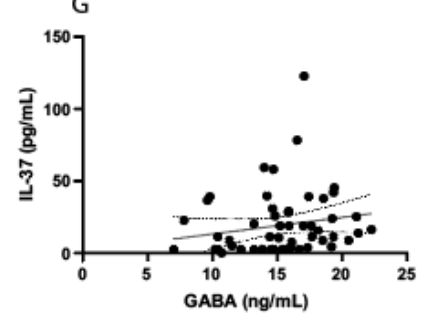

B
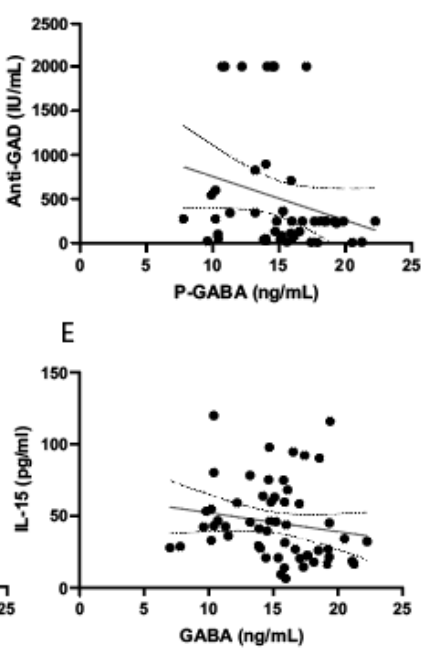

C
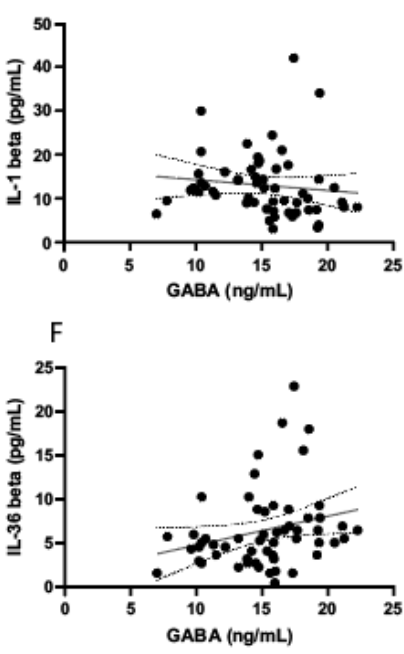

Figure 1. Circulating endogenous GABA levels in healthy controls and patients with type 1 diabetes. (A) The systemic endogenous levels of GABA were detected using mass spectrometry in healthy controls (HC, $n=45)$, patients with long-standing type 1 diabetes (T1D, $n=60)$, and in patients with new-onset T1D (New T1D, $n=13$ ). No difference in circulating GABA levels was observed in T1D patients when compared to healthy controls. Values are presented as mean \pm SEM. (B) Among the patients with T1D, $n=45$ were positive for GAD-autoantibodies and among these patients, a negative correlation with GABA levels was observed $(r=-0.3, p=0.03)$. Note that the upper limit for the clinically used GAD autoantibody assay is $2000 \mathrm{IU} / \mathrm{mL}$. (C-F) Correlations with the circulating endogenous GABA levels and circulating cytokines were computed in T1D patients $(n=56)$ and were found to be negatively correlated with circulating levels of IL-1 beta (C), IL-12 (D) and IL-15 (E), whereas the GABA levels were positively correlated with IL-36 beta (F) and IL-37 (G).

Endogenous GABA levels were negatively correlated to age in both $\mathrm{HC}(r=-0.35$, $p=0.02)$ and long-standing T1D patients $(r=-0.33, p=0.009)$. In patients with longstanding T1D, GABA levels were also negatively correlated to the age at onset $(r=-0.36$, $p=0.005)$, but not to disease duration $(p=0.7)$. Additionally, GABA levels were positively correlated to fasting glucose $(r=0.26, p=0.04)$, but not HbA1c $(p=0.1)$ in long-standing T1D patients. GABA levels were not correlated to markers of metabolic control in HC (i.e., C-peptide, glucose, $\mathrm{HbA1c}$, or BMI). 
Interestingly, among GAD-positive T1D patients $(n=45)$, a negative correlation was observed between GAD-titers and endogenous GABA levels (Figure 1B). Although the reference limit for GAD-autoantibodies is $>5 \mathrm{IU} / \mathrm{mL}$, values between $5-50$ are often clinically considered as low. There was $n=35 \mathrm{~T} 1 \mathrm{D}$ patients who fulfilled a stricter criterion for GAD positivity ( $>50 \mathrm{IU} / \mathrm{mL}$ ), and in this group, a stronger correlation to GABA levels was observed $(r=-0.40, p=0.018)$. In all T1D patients, GABA levels were positively correlated to IL-37 $(r=0.30, p=0.026)$ and IL-36 beta $(r=0.34, p=0.01)$. Additionally, in T1D patients, a negative correlation was observed between GABA levels and IL-12 $(r=-0.29, p=0.033)$, IL-15 $(r=-0.29, p=0.033)$ and IL-1 beta $(r=-0.28, p=0.034)$ (Figure $1 \mathrm{C}-\mathrm{G}$ ). The levels of circulating cytokines were similar in both $\mathrm{HC}$ and patients with T1D (Supplementary Table S1).

In HC, we observed no correlation between GABA levels and circulating cytokines.

\section{Discussion}

Using mass spectrometry, we found that the systemic levels of endogenous GABA are detectable in both healthy controls and T1D patients with varying disease duration. Interestingly, the circulating levels of GABA are not decreased in long-standing T1D despite the loss of beta-cells. This is in line with our previous study in a smaller cohort, based on another method (ELISA), in which we found that the GABA levels were slightly increased in T1D patients [10]. In addition, we also found that the endogenous GABA levels in patients with new-onset T1D are similar to the levels of HC. In light of recent experimental findings regarding GABAs effect on beta-cell proliferation, it is of interest to highlight that patients with T1D do not have a deficit in endogenous plasma GABA levels. Apparently, the GABA secretion from beta-cells does not impact, or only modestly, affect the systemic levels. This is apparent from the observed similar GABA levels in C-peptide-negative T1D patients (i.e., $<0.01 \mathrm{nmol} / \mathrm{L}$ ) and HC. However, levels of GAD autoantibodies were found to correlate negatively with plasma GABA levels. One could therefore speculate that the presence of GAD-autoantibodies restricts the production of GABA from glutamate. GAD autoantibodies could impact GABA levels by hampering an increase of production in both immune cells and remaining beta-cells. Given the potential impact of GAD-autoantibodies, and the minor systemic effect of GABA secreted from beta-cells, the local levels of endogenous GABA in pancreatic islets could likely be affected without a detectable systemic decrease. Theoretically, local pancreatic GABA levels could be detected using magnetic resonance spectroscopy (MRS), as shown in the brain [16]. However, due to technical limitations related to disturbances from breathing motions, this technique would be difficult to apply for quantification within the pancreas. Even if successful, the resolution would not allow for the detection of pancreatic islets.

Endogenous GABA levels were negatively correlated with age in both $\mathrm{HC}$ and patients with T1D. The source of circulating GABA cannot be discriminated, but given that beta-cells seems to have a minor effect on systemic levels and that the beta-cell mass is maintained rather stable over the lifespan in healthy individuals [17], the decline is most likely not related to the beta-cell mass. However, the decline could be related to the age-related loss of gray matter in the brain, which has been observed to result in decreased levels of GABA in the CNS using MRS [18]. This in turn could affect the systemic GABA levels via the glymphatic drainage system.

We found that the systemic levels of GABA correlated with circulating cytokines in patients with T1D, but not in HC. This highlights GABAs complex role in immune regulation and our previous findings that the effects of GABA on immune cells differ in T1D when compared to immune cells from HC [10]. Of the cytokines found to correlate with GABA levels, IL-1 beta, IL-36, and IL-37, are members of the IL-1 family, which is central to regulating the inflammatory response. Of the 11 known members of the IL-1 family, we also analyzed IL-33 and IL-38, but they were not correlated to GABA levels.

We found that GABA levels positively correlated to IL-36 beta and IL-37 levels. IL36 beta is mainly secreted from monocytes and B-cells, which by activating NF-kappa-B 
and MAPK triggers a pro-inflammatory response. Interleukin-37, however, exerts antiinflammatory effects by suppressing NF-kappa-beta and MAPK activation [19], i.e., an opposite effect to IL-36 beta.

GABA levels were found to negatively correlate with IL-1 beta, IL-12, and IL-15, all pro-inflammatory cytokines. IL-1 beta is considered a key mediator of beta-cell destruction. However, only a low number of islet cells have been found to be positive for IL-1 beta [20], and clinical trials with IL-1 receptor antagonists have failed to show clinical efficacy in T1D [21]. Interleukin-12 is mainly produced by activated monocytes and macrophages, and by binding to its receptor, it activates STAT4, which is essential for maintaining Th1 effector cells [22]. Interleukin-15 is elevated in T1D patients [23], and IL-15-blockade in non-obese diabetic (NOD) mice can reverse manifest disease [24]. Interestingly, we have previously found that the circulating levels of IL-15 are lower in patients with longstanding T1D, which maintain C-peptide despite $>10$ years of disease duration [25]. Taken together, we found that in T1D patients, GABA levels negatively correlate with several pro-inflammatory cytokines. Considering that the local levels of GABA in pancreatic islets may impact resident- and circulating immune cells, this may be of great importance for regulating the immune response within islets. Hence, a decline in beta-cell mass may further enhance an immune mediated response due to the loss of local GABA secretion.

A limitation of the current study is that the source of secreted endogenous GABA was not discriminated. Thus meaning, although the systemic levels are similar in both HC and patients with T1D the local concentration and secretion of GABA in different tissues could still be influenced. Perhaps of most importance the local GABA levels within pancreatic islets are most likely affected in T1D due to the loss of beta-cells.

\section{Conclusions}

The systemic endogenous GABA levels are not altered in patients with long-standing or new-onset T1D, but are negatively correlated with levels of GAD autoantibodies.

Supplementary Materials: The following supporting information can be downloaded at: https:// www.mdpi.com/article/10.3390/biomedicines10010091/s1, Table S1: Analyzed circulating cytokines.

Author Contributions: Conceptualization, B.B., P.-O.C. and D.E.; formal analysis, H.H. and D.E.; funding acquisition, P.-O.C. and D.E.; investigation, H.H., A.E., P.L., K.U. and D.E.; methodology, H.H., K.U., J.B. and D.E.; resources, J.B., P.-O.C. and D.E.; supervision, D.E.; writing-original draft, H.H. and D.E.; writing-review and editing, H.H., A.E., P.L., K.U., B.B., P.-O.C. and D.E. All authors have read and agreed to the published version of the manuscript.

Funding: This research was funded by Barndiabetesfonden, the Swedish Society for Medical Research, Diabetesfonden, Vetenskapsrådet and Exodiab. Funders were not involved in the study design, acquisition, analysis, and interpretation of data or writing of this article.

Institutional Review Board Statement: The study was approved by the Regional Research Ethical Committee in Uppsala and was conducted in accordance with the principles of the Declaration of Helsinki as revised in 2013. All participants were provided oral and written information and signed a written consent before inclusion in the study.

Informed Consent Statement: Informed consent was obtained from all subjects involved in the study.

Data Availability Statement: Data will be made available upon reasonable request.

Acknowledgments: Research nurses Rebecka Hilmius and Karin Kjellström, Uppsala University Hospital, Sweden, are gratefully acknowledged for their skilled assistance. We would also like to thank the team from the Translational Plasma Profiling Facility at SciLifeLab for support and the generation of cytokine data for this project.

Conflicts of Interest: Daniel Espes and Per-Ola Carlsson are listed as co-inventors for a patent application regarding therapeutic effects of a controlled-release formulation of GABA submitted by Diamyd Medical AB, but do not have any financial interests in Diamyd Medical AB. Bryndis Birnir is a co-inventor for a patent WO-2019162403-A1, GABA receptor agonists for treatment of disorders influenced by dysfunctional beta cells. The other authors declare no conflict of interest. The funders 
had no role in the design of the study; in the collection, analyses, or interpretation of data; in the writing of the manuscript, or in the decision to publish the results.

\section{References}

1. Jin, Z.; Mendu, S.K.; Birnir, B. GABA is an effective immunomodulatory molecule. Amino Acids 2013, 45, 87-94. [CrossRef] [PubMed]

2. Taniguchi, H.; Okada, Y.; Seguchi, H.; Shimada, C.; Seki, M.; Tsutou, A.; Baba, S. High concentration of gamma-aminobutyric acid in pancreatic beta cells. Diabetes 1979, 28, 629-633. [CrossRef] [PubMed]

3. Bu, D.F.; Erlander, M.G.; Hitz, B.C.; Tillakaratne, N.J.; Kaufman, D.L.; Wagner-McPherson, C.B.; Evans, G.A.; Tobin, A.J. Two human glutamate decarboxylases, 65-kDa GAD and 67-kDa GAD, are each encoded by a single gene. Proc. Natl. Acad. Sci. USA 1992, 89, 2115-2119. [CrossRef] [PubMed]

4. $\quad$ Petersen, J.S.; Dyrberg, T.; Karlsen, A.E.; Molvig, J.; Michelsen, B.; Nerup, J.; Mandrup-Poulsen, T. Glutamic acid decarboxylase (GAD65) autoantibodies in prediction of beta-cell function and remission in recent-onset IDDM after cyclosporin treatment. The Canadian-European Randomized Control Trial Group. Diabetes 1994, 43, 1291-1296. [CrossRef] [PubMed]

5. Tian, J.; Chau, C.; Hales, T.G.; Kaufman, D.L. GABA(A) receptors mediate inhibition of T cell responses. J. Neuroimmunol. 1999, 96, 21-28. [CrossRef]

6. Bhat, R.; Axtell, R.; Mitra, A.; Miranda, M.; Lock, C.; Tsien, R.W.; Steinman, L. Inhibitory role for GABA in autoimmune inflammation. Proc. Natl. Acad. Sci. USA 2010, 107, 2580-2585. [CrossRef] [PubMed]

7. $\quad$ Fuks, J.M.; Arrighi, R.B.; Weidner, J.M.; Kumar Mendu, S.; Jin, Z.; Wallin, R.P.; Rethi, B.; Birnir, B.; Barragan, A. GABAergic signaling is linked to a hypermigratory phenotype in dendritic cells infected by Toxoplasma gondii. PLoS Pathog. 2012, 8, e1003051. [CrossRef]

8. Menegaz, D.; Hagan, D.W.; Almaca, J.; Cianciaruso, C.; Rodriguez-Diaz, R.; Molina, J.; Dolan, R.M.; Becker, M.W.; Schwalie, P.C.; Nano, R.; et al. Mechanism and effects of pulsatile GABA secretion from cytosolic pools in the human beta cell. Nat. Metab. 2019, 1, 1110-1126. [CrossRef] [PubMed]

9. Plog, B.A.; Nedergaard, M. The Glymphatic System in Central Nervous System Health and Disease: Past, Present, and Future. Annu. Rev. Pathol. 2018, 13, 379-394. [CrossRef]

10. Bhandage, A.K.; Jin, Z.; Korol, S.V.; Shen, Q.; Pei, Y.; Deng, Q.; Espes, D.; Carlsson, P.O.; Kamali-Moghaddam, M.; Birnir, B. GABA Regulates Release of Inflammatory Cytokines From Peripheral Blood Mononuclear Cells and CD4(+) T Cells and Is Immunosuppressive in Type 1 Diabetes. EBioMedicine 2018, 30, 283-294. [CrossRef] [PubMed]

11. Tian, J.; Dang, H.; Chen, Z.; Guan, A.; Jin, Y.; Atkinson, M.A.; Kaufman, D.L. gamma-Aminobutyric acid regulates both the survival and replication of human beta-cells. Diabetes 2013, 62, 3760-3765. [CrossRef]

12. Untereiner, A.; Xu, J.; Bhattacharjee, A.; Cabrera, O.; Hu, C.; Dai, F.F.; Wheeler, M.B. gamma-aminobutyric acid stimulates beta-cell proliferation through the mTORC1/p70S6K pathway, an effect amplified by Ly49, a novel gamma-aminobutyric acid type A receptor positive allosteric modulator. Diabetes Obes. Metab. 2020, 22, 2021-2031. [CrossRef]

13. Ben-Othman, N.; Vieira, A.; Courtney, M.; Record, F.; Gjernes, E.; Avolio, F.; Hadzic, B.; Druelle, N.; Napolitano, T.; Navarro-Sanz, S.; et al. Long-Term GABA Administration Induces Alpha Cell-Mediated Beta-like Cell Neogenesis. Cell 2017, 168, 73-85.e11. [CrossRef] [PubMed]

14. Soltani, N.; Qiu, H.; Aleksic, M.; Glinka, Y.; Zhao, F.; Liu, R.; Li, Y.; Zhang, N.; Chakrabarti, R.; Ng, T.; et al. GABA exerts protective and regenerative effects on islet beta cells and reverses diabetes. Proc. Natl. Acad. Sci. USA 2011, 108, 11692-11697. [CrossRef]

15. Espes, D.; Liljeback, H.; Hill, H.; Elksnis, A.; Caballero-Corbalan, J.; Carlsson, P.O. GABA induces a hormonal counter-regulatory response in subjects with long-standing type 1 diabetes. BMJ Open Diabetes Res. Care 2021, 9, e002442. [CrossRef] [PubMed]

16. Persson, J.; Wall, A.; Weis, J.; Gingnell, M.; Antoni, G.; Lubberink, M.; Boden, R. Inhibitory and excitatory neurotransmitter systems in depressed and healthy: A positron emission tomography and magnetic resonance spectroscopy study. Psychiatry Res. Neuroimaging 2021, 315, 111327. [CrossRef] [PubMed]

17. Saisho, Y.; Butler, A.E.; Manesso, E.; Elashoff, D.; Rizza, R.A.; Butler, P.C. beta-cell mass and turnover in humans: Effects of obesity and aging. Diabetes Care 2013, 36, 111-117. [CrossRef] [PubMed]

18. Maes, C.; Hermans, L.; Pauwels, L.; Chalavi, S.; Leunissen, I.; Levin, O.; Cuypers, K.; Peeters, R.; Sunaert, S.; Mantini, D.; et al. Age-related differences in GABA levels are driven by bulk tissue changes. Hum. Brain Mapp. 2018, 39, 3652-3662. [CrossRef] [PubMed]

19. Su, Z.; Tao, X. Current Understanding of IL-37 in Human Health and Disease. Front. Immunol. 2021, 12, 696605. [CrossRef] [PubMed]

20. Reddy, S.; Krogvold, L.; Martin, C.; Holland, R.; Choi, J.; Woo, H.; Wu, F.; Dahl-Jorgensen, K. Distribution of IL-1beta immunoreactive cells in pancreatic biopsies from living volunteers with new-onset type 1 diabetes: Comparison with donors without diabetes and with longer duration of disease. Diabetologia 2018, 61, 1362-1373. [CrossRef]

21. Cabrera, S.M.; Wang, X.; Chen, Y.G.; Jia, S.; Kaldunski, M.L.; Greenbaum, C.J.; Type 1 Diabetes TrialNet Canakinumab Study Group; Mandrup-Poulsen, T.; AIDA Study Group; Hessner, M.J. Interleukin-1 antagonism moderates the inflammatory state associated with Type 1 diabetes during clinical trials conducted at disease onset. Eur. J. Immunol. 2016, 46, 1030-1046. [CrossRef] [PubMed] 
22. Gee, K.; Guzzo, C.; Che Mat, N.F.; Ma, W.; Kumar, A. The IL-12 family of cytokines in infection, inflammation and autoimmune disorders. Inflamm. Allergy Drug Targets 2009, 8, 40-52. [CrossRef] [PubMed]

23. Kuczynski, S.; Winiarska, H.; Abramczyk, M.; Szczawinska, K.; Wierusz-Wysocka, B.; Dworacka, M. IL-15 is elevated in serum patients with type 1 diabetes mellitus. Diabetes Res. Clin. Pract. 2005, 69, 231-236. [CrossRef] [PubMed]

24. Chen, J.; Feigenbaum, L.; Awasthi, P.; Butcher, D.O.; Anver, M.R.; Golubeva, Y.G.; Bamford, R.; Zhang, X.; St Claire, M.B.; Thomas, C.J.; et al. Insulin-dependent diabetes induced by pancreatic beta cell expression of IL-15 and IL-15Ralpha. Proc. Natl. Acad. Sci. USA 2013, 110, 13534-13539. [CrossRef]

25. Espes, D.; Singh, K.; Sandler, S.; Carlsson, P.O. Increased Interleukin-35 Levels in Patients With Type 1 Diabetes with Remaining C-Peptide. Diabetes Care 2017, 40, 1090-1095. [CrossRef] [PubMed] 